\title{
THE SUBSTANTIAL MECHANISMS OF STEP VOLTAGE EFFECTS
}

\author{
N. Kitagawa ${ }^{(1)}$, M. Ohashi ${ }^{(2)}$ and T. Ishikawa ${ }^{(3)}$ \\ (1)Central Lightning Protection Inc., [home address] 422-16 Okubo-Ryoke, Saitama-shi, \\ 338-0826 Japan \\ (2)Tokyo Denryoku Co., [home address] 1-31-12 Saiwaichyo, Fuchyu-shi, 183-0054 Japan \\ (3)Defense Medical Academy, [home address] 6-22-8 Sakuradai, Nerima-ku, Tokyo, \\ 176-0002 Japan
}

\begin{abstract}
The injuries caused by the potential difference on the ground surface due to the ground flash are called step voltage injuries. The authors have examined the injuries of this category, based on the numerous field investigations of human lightning accidents. It is found that two different mechanisms of current flow along the ground surface are associated with the ground flash. When a lightning flash reaches the ground, the lightning current usually flows through the upper layer of the ground as conduction current. If a person contacts the ground with plural parts of his body, he is subjected to the potential difference between those two parts but the effects he receives are temporary and slight. Sometimes, when a lightning flash reaches the ground, a surface arc discharge develops along the ground surface together with the flow of the conduction current in the ground. If a person is situated on this discharge path, he receives severe effects. He suffers thermal injuries and paralysis, he may lose his walking ability and may be killed in worst case.

To compile the safety guide against lighting hazards, these two different mechanisms of current flow along the ground surface due to the ground flash should be considered.
\end{abstract}

Keywords: lightning, ground flash, step voltage, safety guide

\section{Introduction}

A person standing near the struck point of a ground flash is subjected to a potential difference between his two feet. This potential difference is called step voltage and the literature by Golde and Lee (1976) carries the following equation that indicates the amount of the step voltage $u$ :

$\mathrm{u}=\mathrm{i} \rho /(2 \pi) \times \mathrm{s} /\{\mathrm{d}(\mathrm{d}+\mathrm{s})\}$

here, $\mathrm{i}, \mathrm{s}$ and $\mathrm{d}$ are the lightning current, the distance between his both feet and the distance between the struck point and his nearer foot, respectively.

The equation assumes the hemispherically uniform flow of lightning current into the ground. However, in the actual case, lightning current flows mainly through the upper layer of the earth and consequently the equation does not represent the real step voltage. Since there is no formula that properly evaluates the step voltage, the nature of the step voltage has to be studied based on the field investigations of human lightning accidents.

When a person contacts the ground surface with plural parts of his body near the struck point, he is subjected to a potential difference between those two parts. This potential difference is generally called the step voltage.

\section{Studies of the Lightning on Human Bodies}

The authors organized the research group, consisting of physicists, physicians and high voltage engineers, for the study of the lightning discharge on human bodies. The group has carried out the field investigations of human lightning accidents and has accumulated 70 cases 
Table 1. 33 cases that involved people who are subjected to step voltage

\begin{tabular}{|c|c|c|c|c|}
\hline name of places & date & $\begin{array}{l}\text { number of people } \\
\text { received direct or } \\
\text { side flashes }\end{array}$ & $\begin{array}{l}\text { number of } \\
\text { people subjected } \\
\text { to step voltage }\end{array}$ & $\begin{array}{l}\text { number of } \\
\text { people who } \\
\text { actually } \\
\text { received injuries } \\
\text { on their lower } \\
\text { bodies } \\
\end{array}$ \\
\hline Setagaya & $65 / 07 / 16$ & 1-direct-d & 3 & 0 \\
\hline Asamayama & ‘69/07/26 & 1-direct-d & 13 & 0 \\
\hline Wada-mura & $571 / 07 / 05$ & 1-direct-d & 18 & 0 \\
\hline Susono & $72 / 08 / 01$ & 0 & 5 & 4 \\
\hline Noda & $73 / 08 / 19$ & 1-direct-d & 2 & 2 \\
\hline Higashi-yuri-machi & $75 / 08 / 22$ & 2-side-s & 13 & 2 \\
\hline Kami-igusa & ‘77/0719 & 1-direct-d & 1 & 0 \\
\hline Nishitake & $78 / 05 / 02$ & 1-side-s & 2 & 0 \\
\hline Mochizuki-machi & $78 / 07 / 07$ & 1-side-d & 3 & 0 \\
\hline Hashimoto & $78 / 07 / 09$ & 1-direct-d & 3 & 0 \\
\hline Kutsuzawa & ‘78/07/11 & 1-direct-d & 1 & 0 \\
\hline Gozaishyotake & $78 / 08 / 17$ & 1-side-s & 1 & 0 \\
\hline Fukae & $79 / 05 / 26$ & 1-direct-d & 1 & 0 \\
\hline Kohriyama & '79/05/26 & 1-direct-d & 9. & 0 \\
\hline Tsushima & $79 / 05 / 27$ & 1-direct-d & 2 & 1 \\
\hline Uminokuchi & $79 / 07 / 25$ & 1-direct-d & 2 & 1 \\
\hline Hakubatake & $79 / 07 / 28$ & 1-direct-s & 4 & 1 \\
\hline Yarigatake & '79/08/06 & 1-direct-d & 2 & 1 \\
\hline Korengesan & $78 / 08 / 22$ & 1-direct-d & 2 & 0 \\
\hline Itsukaichi-shi & '81/07/21 & 1-direct-d & 2 & 2 \\
\hline Takaiwayama & '81/07/21 & 1-side-s & 1 & 1 \\
\hline Fuji-gogome & $82 / 08 / 07$ & 1-side-d & 7 & 0 \\
\hline Fuji-kugogoshyaku & '82/08/08 & 0 & 7 & 1 \\
\hline Akita-komagatake & $83 / 06 / 19$ & 0 & 13 & 2 \\
\hline Seto & ' $84 / 07 / 20$ & 1-direct-d & 1 & 0 \\
\hline Kiryu & $84 / 09 / 21$ & 1-direct-d & 2 & 0 \\
\hline Fuji-hokuroku & '85/09/02 & 2-side-d & 6 & 6 \\
\hline Kani & $87 / 07 / 15$ & 1-direct-d & 5 & 0 \\
\hline Seijyou & '87/08/14 & 1-direct-s & 5 & 0 \\
\hline Kubotesan & ‘88/07/12 & 1-side-s & 15 & 13 \\
\hline Omiya-hasunuma & $90 / 05 / 15$ & 2-side-s & 12 & 0 \\
\hline Hannoh & ‘91/06/29 & 1-direct-d & 13 & 0 \\
\hline Ohyama & $92 / 11 / 01$ & 1-direct-d, 2-direct-s & 6 & 0 \\
\hline total number & 3 & & 182 & 37 \\
\hline
\end{tabular}

1-direct-d: 1 person was struck by a direct flash and died.

2-side-s: 2 persons were struck by side flashes and severely injured. 
from 1965 to 1996 (Kitagawa, Ohashi, Tsuyuki, and Ishikawa, 1996). The group has also executed numerous simulation experiments, imposing high voltage impulses on dummies and various kinds of animals and obtained the data that enabled the authentic interpretation of the results of the field investigations of human lightning accidents. Based on these studies, Kitagawa, Turumi, Ishikawa, and Ohashi (1985) elucidated the essential feature of the lightning discharges on human bodies. In the present article, the step voltage effect will be clarified by surveying the 70 investigated cases.

\section{Investigation of the Step Voltage Effect Based on the Field Investigations of Human Lightning Accidents}

Fig.1. illustrates all the possible postures by which people are subjected to step voltage. Among the 70 investigated cases, 33 cases involved people who took one of the postures shown in Fig.1. For the individual accident of the 33 cases, Table 1 indicates the name of the place, the date of the accidents, the number of people who took the postures

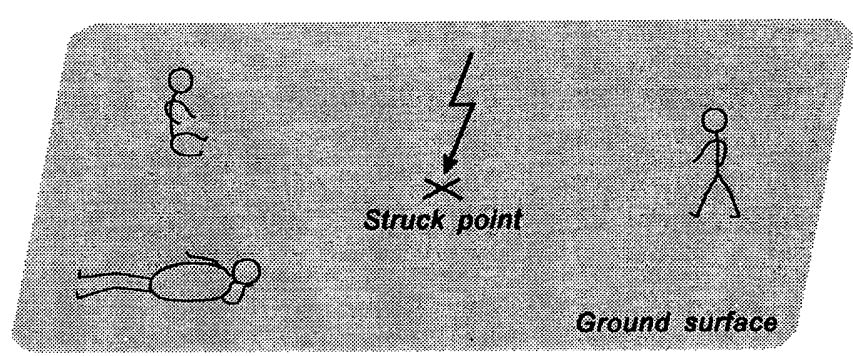

Fig.1. The postures by which people are subjected to step voltage subjected to the step voltage and the number of people who actually suffered injuries on their parts of bodies contacting the ground surface. Table 1 . also indicates the injuries caused by direct strikes and/or side flashes, showing the number of victims, ways of strikes (direct strike or side flash) and the effects (death or severe injury). For instance, "1-direct-d" means 1 person was struck by a direct flash and died, and " 2 -side-s" means 2 persons were struck by side flashes and were severely injured. In the 33 cases, the total number of people who actually suffered injuries on their parts of bodies contacting the ground surface was 37 , while the total number of people who took the postures subjected to the step voltage(one of the postures shown in Fig.1.) was 182. It turned out that among the people who took the postures subjected to the step voltage, only the small number of people actually suffered step voltage injuries and the rest major number of people were free from substantial injuries .

Surveying the 33cases, it was found that they were classified into the following two types: Type (1): No surface arc discharge developed on ground surface and people who took one of the postures shown in Fig.1. were sightly or not injured.

Type (2): A surface arc discharge developed on ground surface and people who were situated on the discharge path were appreciably or severely injured.

In the following sections, three cases are described as examples, among which one is classified to Type (1) and the rest two are classified to Type (2). In describing the individual accident, the name of the place is used to identify the accident.

\section{Fukae Accident}

The accident occurred on May 26, 1979 about 14:10 JST at Fukae Baseball Field in Kobe City. It was cloudy and not raining. The ground surface was dry. While the baseball match was going on, a catcher passed a ball, a runner B started from a first base and was going to touch a second base. A second base man $A$

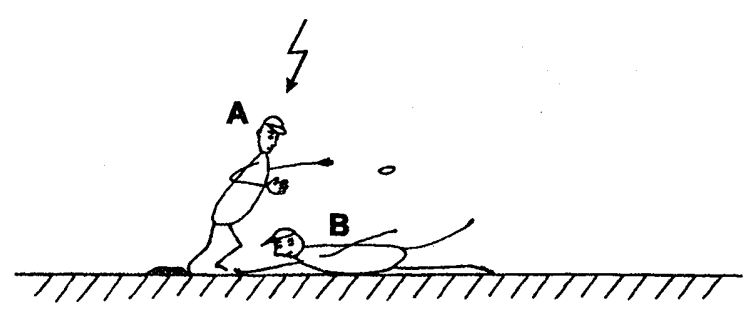

Fig.2. Sketch of Fukae Accident 
returned to the base. At the moment, lightning struck $A$. This situation is illustrated in Fig.2. A died instantly and $B$ lost his consciousness. 5 minutes later, $B$ recovered his consciousness and visited a hospital by himself. At the arrival time to the hospital, his pulsation was somewhat fast. However, he soon recovered his normal physical condition and was discharged from the hospital on the next day.

This case is classified to Type (1) and is notable because the runner got no appreciable injuries though his situation seemed to be subjected to the most severe step voltage effect.

At Kami-igusa and Hashimoto Accidents, people were playing baseball. In each case, a player taking a posture subjected to the step voltage was situated within a few meters from a struck person and still suffered no injuries. These two cases are classified to Type (1).

\section{Takaiwayama Accident}

The accident occurred on July 21, 1981 about 13:20 JST near the top of Takaiwayama $(915 \mathrm{~m}$ above sea level). Two mountain climbers $A$ and $B$ were resting in a wood near the mountain top. A sat on a big stone, received side flash from a twig of a tree above his head and lost his consciousness. B sat in front of $A$, witnessed one stream of arc run underneath his body and felt severe pain on his both lower limbs. His pain was temporal and B started to walk down the mountain for rescue. About 40 minutes later, A recovered his consciousness, felt pain on his whole chest and noticed his both lower limbs were paralyzed. One hour later, A recovered from the pain and paralysis, walked down the mountain and asked rescue at the police station. Meanwhile, B lost his way in the mountain and reached the police station on next day.

$A$ received a linear thermal injury along his lower right limb which was deduced to be caused by surface arc discharge along the body surface. A was cured of injuries after 10 days. B suffered difficulty in hearing and slight burns on his right arm. B recovered hearing ability in a week.

\section{Akita-komagatake Accident}

The accident occurred on June 19, 1983 about 13:30 JST around the guidepost $(1583 \mathrm{~m}$ above sea level) at the mountain pass near the top of Akita-komagatake. While 13 mountain climbers were lowering their postures, waiting the cease of lightning activity, a ground flash struck the guidepost. Fig. 4 . shows the sketch of the struck guidepost and its neighborhood together with the sketch of the original guidepost. The center pole was damaged, while the rest parts of the guidepost remained. It was raining and the ground surface was wet. 13 climbers situated near the guidepost were affected by lightning. 3 climbers, A, B and C
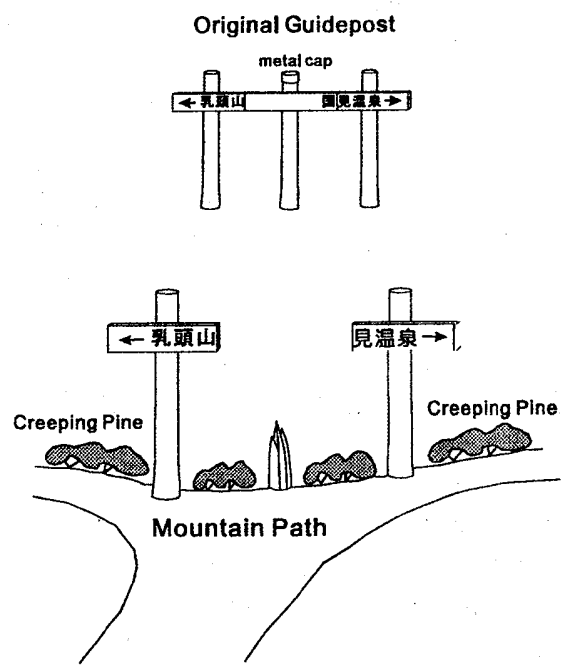

Fig.4 The struck guidepost and the surrounding together with the original guidepost 
were severely injured and hospitalized. The rest 10 climbers were injured to some degree, treated as outpatients and were all cured in a few days. A and $C$ lost walking ability and were carried on stretchers to the hospital. A suffered pain on both his lower limbs

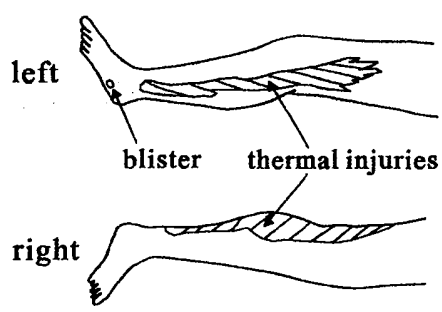

Fig.5. Lower limbs of $A$

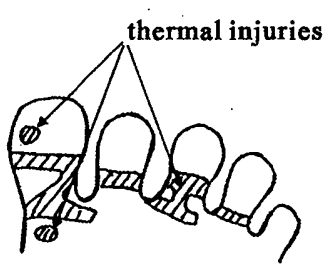

Fig.6. Ground side of thumbs of the left foot of $C$

and received wide thermal injuries from thighs to feet as shown in Fig.5. A recovered in a week. $B$ was blown off about $3 \mathrm{~m}$, lost his consciousness momentarily and suffered traumas and slight thermal injuries. B was cured in a week. C suffered thermal injuries on the ground side of his 4 thumbs of the left foot as shown in Fig.6. and had the wound portions sutured. $C$ was cured in 10 days.

The thermal injuries on human bodies are caused only by surface arc discharges along the bodies. Consequently, it is certain that a surface arc discharge on the ground surface developed from the struck point and made its way underneath $A$ and $C$, though an surface arc discharge was not witnessed. This accident is classified to Type (2).

\section{The Disastrous Lightning Accident in Japan Alps}

The accident occurred on August 1, 1967 about 13:40 JST around the top of a rocky peak ( $2640 \mathrm{~m}$ above sea level) near Nishi-Hotakatake. The mountain climbing group of MatsumotoFukashi Senior School was involved in the accidents and eleven students were killed. Matsumoto-Fukashi Senior School (1969) published the book that describes the detail of the accident, namely, the behavior of people, the states of injuries, the medical treatments of victims, the field investigations carried out right after the accident, etc.

The accident is summarized as follows:

At the time of lightning strike, 54 people formed a line along the mountain path located along the sharp ridge of the rocky peak. Fig.7. shows the north-south vertical cross section of the peak and the positions of people when lightning struck the peak. The people were moving from north to south, the front 10 people were on the south slope, the following 8 people were on the top, the

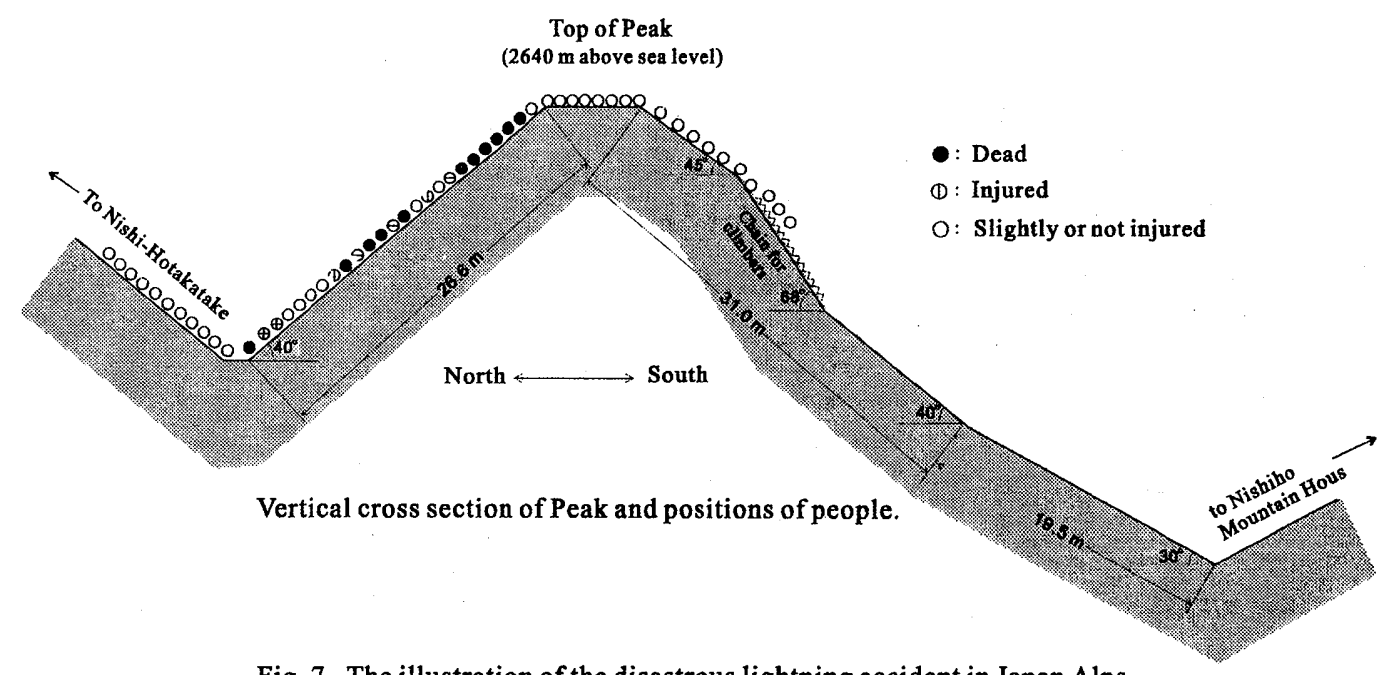

Fig. 7. The illustration of the disastrous lightning accident in Japan Alps 
following 25 people were on the north slope and the rear 11 people were on the slope of the other side of the saddle point. Among 54 people, 46 were the students and teachers of MatsumotoFukashi Senor School. In the figure, black-painted circles, circles with cross signs and simple circles represent dead people, severely injured people and slightly or not injured people, respectively. It is deduced that when the lightning channel reached the peak top, the main lightning current flew as a surface arc discharge along the north ridge of the peak and finally dispersed into the earth at the northern saddle point. Many people situated along the north slope were killed or severely injured. Among them, 9 died of lightning current and 2 died of downfalls.

One of the reason why this ground flash caused so many victims is that the main lightning current flew as a surface arc discharge from the peak top to the saddle point without dissipation. Another reason may be that the ground flash itself was very energetic one. Though the accident is exceptional, the people who were killed or severely injured were all subjected to the Type (2) effect.

\section{Comments on Literatures on Step Voltage}

In the case study presented by Duis and Klasen (1985), two men and one woman stood close to the trunk of a tree, when the tree was struck by lightning. One man died and the rest two persons survived. The authors present the illustration shown in Fig.8. and interpret that the man situated in the center received a side-flash from the tree and the rest two persons were affected by the step voltage. However, the situations of the rest two persons against the tree and the thermal injuries on the woman's face apparently indicate that they also received

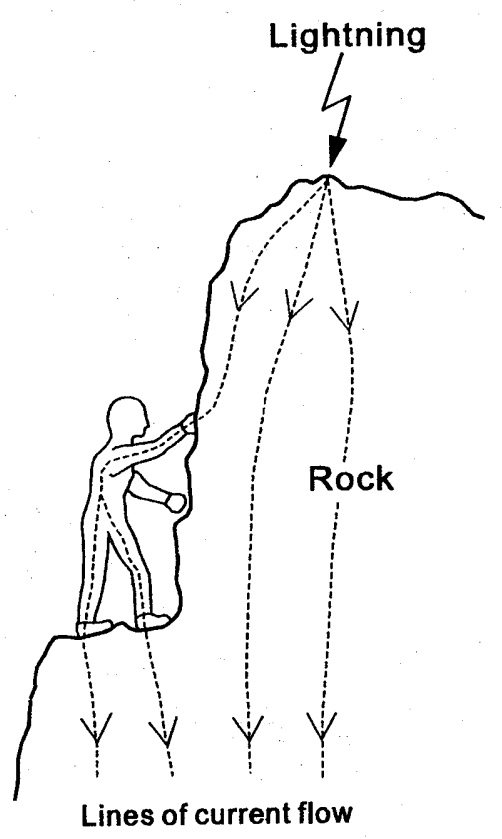

Fig. 9. The illustration of the step voltage effect on a rocky maintain, presented by Hasse and Wiesinger (1982) 
side-flashes from the tree. The two persons had their both lower limbs vasoconstricted. It is highly probable that those effects were caused not by the currents from one foot to the other but by the currents that flew vertically through their whole bodies from the upper bodies to the both lower limbs.

Hasse and Wiesinger (1982) emphasize the danger of the step voltage effect on mountain climbers on rocky mountains. They present the illustration in Fig.9. that indicates the Type (1) effect but this effect will not cause severe effects, because the resistivity of the rock is very high and the current density in the human body is very low. When lightning struck the top of a rocky mountain, it is highly probable that a surface arc discharge develops along the rock surface and causes the Type (2) effect. Therefore, the illustration in Fig.9. should be replaced by the one in Fig.10.

\section{Conclusion}

When a lightning flash reaches the ground, the lightning current usually flows as conduction current through the upper layer of the ground. In this case, a person situated near the struck point, contacting the plural parts of his body on the ground, is subjected to the potential difference between those two parts but the effects he receives are temporary and slight. Sometimes, when a lightning flash reaches the ground, a surface arc discharge develops along the ground surface together with the flow of the conduction current in the ground. If a person is situated on this discharge path, he receives severe injuries. He suffers thermal injuries and paralysis, he may lose his walking ability and may be killed in worst case. When the ground surface is wet, the surface arc discharge is apt to develop, but the general condition for the outbreak of the surface arc discharge is not well known.

When a person is involved in thunderstorms in the outdoor remote from all kinds of buildings, it is recommended to lower himself and minimize the contact area to the ground. It is also recommended to close both ear holes with fingers.

When thunderstorms are anticipated, a person has to leave away from the rocky mountain as fast as possible. If he is situated on any place of the rocky mountain, he is subjected to be fatally or severely injured by a surface arc discharge due to a ground flash to the mountain.

\section{References}

Duis, H.J. ten and H.J. Klasen, Keraunoparalysis, a specific lightning injury, Burns, vol.12, 54-57, 1985.

Golde, R.H. and W.R. Lee, Death by lightning, Proc. IEE, vol.123, no.10R, 1163-1180, 1976. 
Hasse, P., and J. Wiesinger, Handbuch für Blitzschutz und Erdung, p146, Richard Pflaum Verlag, Munich, 1982.

Kitagawa, N., M. Ohashi, A. Tsuyuki, and T. Ishikawa, Clinical and experimental studies on lightning injuries, Proceedings of 10th International Conference on Atmospheric Electricity, 305-308, Osaka, 1996.

Kitagawa, N., S. Turumi, T. Ishikawa, and M. Ohashi, The nature of lightning discharge on human bodies and the basis for safety and protection, Proceedings of 18th International Conference on Lightning Protection, 435-438, Munich, 1985.

Matsumoto-Fukashi Senior High School, An Accident Caused by Lightning on Doppyo Peak at Mt. Nishihotaka in the North Japan Alps, Matsumoto-Fukashi Senior High School, Matsumoto City, 1969.

(Received June 5, 2001; Revised July 19, 2001;

Accepted July 30, 2001) 